\title{
Dynamic changes in seagrass assemblages under eutrophication and implications for recovery
}

\author{
P.G. Cardoso ${ }^{\text {a,* }}$, M.A. Pardal ${ }^{\text {a }}$, A.I. Lilleb $\varnothing^{\text {a }}$, S.M. Ferreira ${ }^{\text {a }}$, \\ D. Raffaelli ${ }^{\mathrm{b}}$, J.C. Marques ${ }^{\mathrm{a}}$ \\ ${ }^{a}$ Department of Zoology, IMAR-Institute of Marine Research, \\ University of Coimbra, 3004-517 Coimbra, Portugal \\ ${ }^{\mathrm{b}}$ Environment Department, University of York, Heslington, York YO10 5DD, UK
}

Received 10 March 2003; received in revised form 20 October 2003; accepted 22 October 2003

\begin{abstract}
Over the last 20 years, loss of seagrass beds, often related with increased eutrophication, became a common problem worldwide. In the Mondego estuary (Portugal), eutrophication has triggered serious biological changes, which led to an overall increase in primary production and to a progressive replacement of seagrass Zostera noltii beds by coarser sediments and opportunistic macroalgae.

The effects of this eutrophication on benthic assemblages were studied along a spatial gradient in the Mondego estuary from 1993 to 1995. Over these short temporal and small spatial scales, distinct changes in the structure of the macrobenthic communities were observed. One of the main structural modifications was the decrease in species diversity along the eutrophication gradient and over time, with a marked impoverishment of the most disturbed inner area. Other changes included an increase in detritivores and a decline in herbivores together with a significant increase in small depositfeeding polychaetes.

In the long term, sustained eutrophication of this estuary is expected to lead to complete replacement of seagrass habitat by unvegetated coarser sediments, occasionally covered by green macroalgal blooms and dominated by opportunistic invertebrate taxa. Recovery from this situation may not only require reduction in nutrient loadings to the estuary, but also active seagrass restoration programmes to reverse the positive feedback processes thought to be presently taking place.
\end{abstract}

(C) 2003 Elsevier B.V. All rights reserved.

Keywords: Eutrophication; Seagrass beds; Hysteresis; Macrobenthic community; Species diversity; Trophic structure

* Corresponding author.

E-mail address: gcardoso@ci.uc.pt (P.G. Cardoso). 


\section{Introduction}

Declines in seagrass beds have been documented for many areas of the eastern Atlantic (reviewed in Schramm and Nienhuis, 1996), including much of the Iberian Peninsula (Niell et al., 1996; Oliveira and Cabecadas, 1996), often associated with increased eutrophication. The mechanisms responsible for seagrass decline under eutrophication are complex and probably involve a suite of direct and indirect effects of changes in water quality, smothering by green macroalgal blooms (Den Hartog and Phillips, 2000), and competition for light and nutrients with epiphytic microalgae and with phytoplankton (Nienhuis, 1996). Loss of the seagrass plants leads to changes in the associated biological communities (Reise et al., 1989; Flindt et al., 1997) and the functions, services and goods that seagrass beds provide (Duarte, 2000).

The temporal trajectory of the eutrophication-induced ecological changes that take place in seagrass beds with eutrophication is not well-documented. This is partly because the early stages of the process are so gradual that they usually are not recognised until changes are well under way, and partly because, for many locations, the major changes occurred decades ago (Schramm and Nienhuis, 1996). However, an appreciation of such trajectories is vital if remedial and restorative programmes for seagrass beds are to be successful (Van Katwijk and Hermus, 2000; Reise, 2002). Hobbs and Nortton (1996) provide a framework pointing out that restoration will only be effective if all the processes which have driven the observed ecological changes are understood and addressed, and this may include additional engineered disturbance to replace an ecosystem component, as well as removing the original stressors. For aquatic systems, there is much evidence that nutrient-induced changes in the growth of opportunistic macroalgae and/or phytoplankton are implicated in catastrophic shifts in aquatic communities ranging from freshwater lakes to coral reefs (Scheffer et al., 2001) because of nonlinearities (hysteresis) in the dynamics of the systems as they change. These systems may be pushed into an alternate stable state by positive feedback processes from which recovery is very difficult to engineer (Hobbs and Nortton, 1996; Scheffer et al., 2001). Such positive feedback dynamics may explain why long-term recovery of seagrass beds throughout much of Europe and Australia has been painfully slow or non-existent (Kendrick et al., 2002) despite reductions in nutrient loadings. The mechanisms underlying potential hysteresis in seagrass beds are likely to be associated with the positive feedback processes leading to changes in the local physical environment following the loss of plants, i.e. the further loss of sediments, especially fine material, and sediment resuspension, which further accelerates bed decline (Duarte, 1995, 2000; Reise, 2002; Schramm, 1996; Widdows and Brinsley, 2002; Van Katwijk and Hermus, 2000; Van de Koppel et al., 2001). Clearly, the sediment issues (ecosystem components) need to be addressed as well as the stressors (nutrients). In the present study, we describe the ecological changes that have taken place over relatively short temporal and small spatial scales in a welldocumented seagrass habitat experiencing eutrophication, the Mondego estuary, Portugal, and comment on the likely form of the dynamics of this system under change. 


\section{Materials and methods}

\subsection{Study site and sampling programme}

The Mondego estuary is located on the Atlantic coast of Portugal $\left(40^{\circ} 8^{\prime} \mathrm{N}\right.$, $8^{\circ} 50^{\prime} \mathrm{W}$ ). It is about $7 \mathrm{~km}$ long and is $2-3 \mathrm{~km}$ across at its widest part. Wetland habitats occupy about 1072 ha (Lopes et al., 2000). The estuary comprises two contrasting arms, northern and southern, separated by Murraceira island, formed by the deposition of detrital materials transported by the river, as the river floodplain (Fig. 1). The northern arm is deeper (4-8 $\mathrm{m}$ during high tide, tidal range 1-3 $\mathrm{m}$ ) and constitutes the principal navigation channel and the location of the Figueira da Foz harbour. The southern arm is shallower (2-4 m during high tide, tidal range $1-3 \mathrm{~m}$ ) and is almost silted up in the upper zones, so that the freshwater outflow is mainly via the northern arm. Circulation in the southern arm is mostly dependent on the tides and on the freshwater input from the Pranto River, a small tributary. The discharge from this tributary is controlled by a sluice and is regulated according to the water needs of rice fields in the Mondego Valley. The estuary supports several industrial activities and aquacultures, as well as receiving nutrients from 15000 ha of cultivated land upstream. Green macroalgal mats have appeared regularly over the last 20 years with a concurrent decline in seagrass beds (Marques et al., 1993a,b, 1997; Flindt et al., 1997; Lillebø et al., 1999; Pardal et al., 2000; Martins et al., 2001; Cardoso et al., 2002; Dolbeth et al., in press).

Three different study areas were established along a spatial gradient in the southern arm of the Mondego estuary: (1) the Zostera noltii beds, corresponding to a noneutrophic area, (2) an intermediate area and (3) the most eutrophic area (Fig. 1).

The $Z$. noltii beds are characterised by higher salinity values $\left(20-30 \mathrm{~g} \mathrm{l}^{-1}\right)$, lower total inorganic nitrogen concentrations $\left(15-30 \mu \mathrm{mol} \mathrm{N}^{-1}\right)$ and higher water-flow velocities $\left(1.2-1.4 \mathrm{~m} \mathrm{~s}^{-1}\right)$ comparatively to the other areas. The mean organic matter content of the sediment is $6.8 \pm 0.99 \%$ ( \pm S.D.). (Pardal et al., 2000; Martins et al., 2001; Cardoso et al., 2002). In the 1980s, Z. noltii beds occupied a broad expanse along the southern arm $\left(150000 \mathrm{~m}^{2}\right)$ reaching the inner most parts of the estuary. By the mid-1990s, Z. noltii had become restricted to a small patch $\left(200 \mathrm{~m}^{2}\right)$ located downstream, having been replaced elsewhere by blooming, fast-growing green macroalgae (free-floating forms) (Fig. 1). Mapping of benthic vegetation was done based on field observations, aerial photographs and GIS methodology (ArcView GIS version 8.2).

The intermediate area is located just upstream of the Z. noltii beds and has no seagrass cover although some rhizomes remain in the sediment. The physical-chemical conditions are otherwise similar to those of the $Z$. noltii beds.

The most eutrophic area is upstream in the inner part of the estuary. It comprises a sandy-muddy sediment characterised by the absence of seagrasses (for more than 15 years) and now covered seasonally by green macroalgae, especially Enteromorpha sp. (Pardal et al., 2000; Martins et al., 2001; Cardoso et al., 2002). In contrast to the $Z$. noltii beds, this area has lower salinities $\left(15-25 \mathrm{~g}^{-1}\right)$, higher total inorganic nitrogen concentrations $\left(30-50 \mu \mathrm{mol} \mathrm{N}^{-1}\right)$ and lower water-flows 


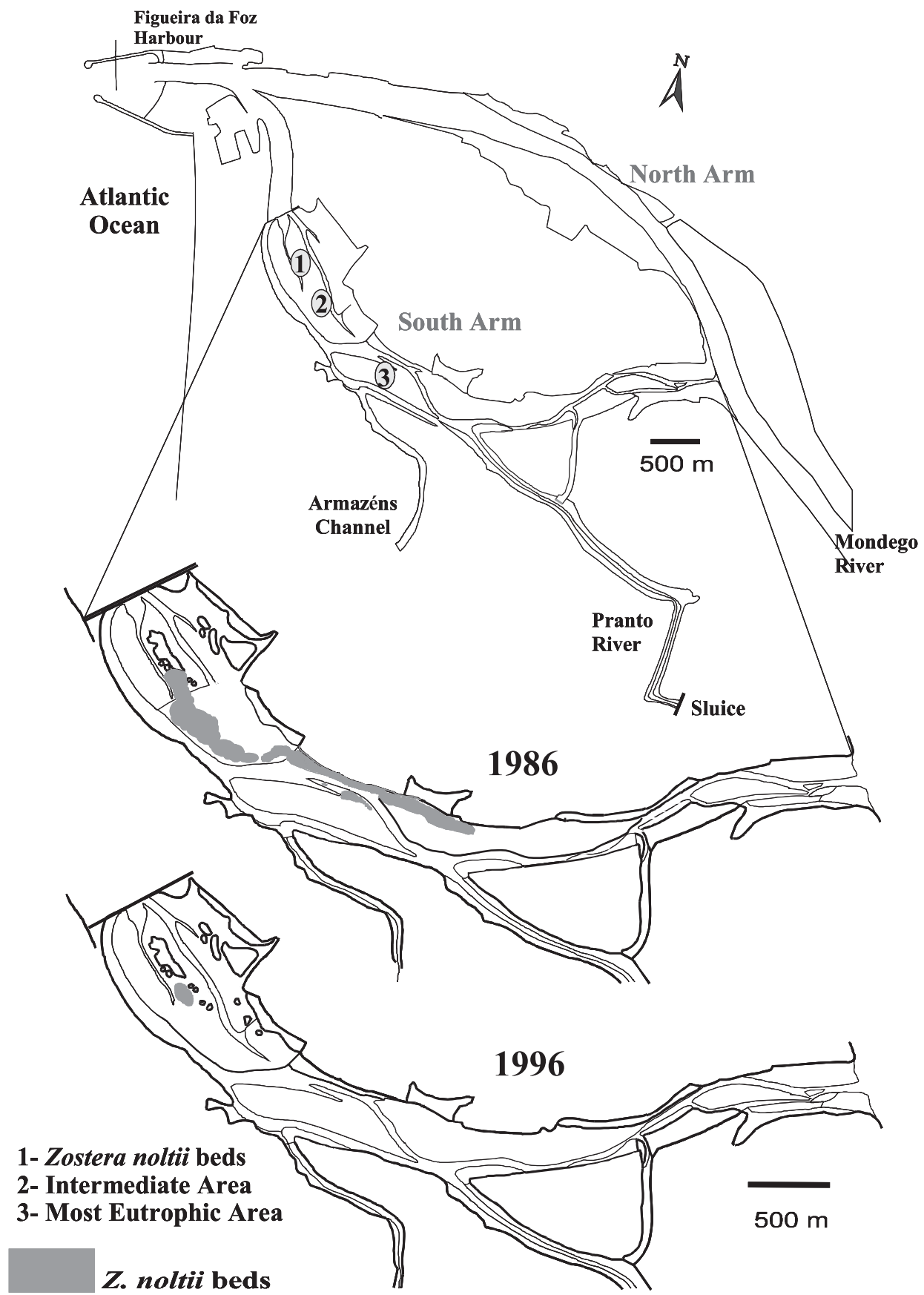

Fig. 1. Location of the sampling areas in the south arm of the Mondego estuary and comparison of the area covered with Z. noltii between 1986 and 1996. 
$\left(0.8-1.2 \mathrm{~m} \mathrm{~s}^{-1}\right)$. The mean organic matter content of the sediment is $3.7 \pm 1.0 \%$ ( \pm S.D.).

Sampling of the macrobenthic community was carried out from January 1993 to September 1995. Samples were collected fortnightly in the first 18 months and monthly during the rest of the study period. On each sampling occasion, 6-10 cores (13.5 cm diameter) were taken to a depth of $20 \mathrm{~cm}$. Samples were washed in estuarine water through a $500-\mu \mathrm{m}$ mesh at each sampling station and the fauna retained preserved in $4 \%$ buffered formalin. Later, animals were separated and kept in $70 \%$ ethanol.

On each sampling occasion (monthly) and at each station, environmental parameters were measured in situ, in low water pools and water sampled for physical and chemical analysis (e.g. temperature, salinity, dissolved oxygen, $\mathrm{pH}$, total inorganic nitrogenic, dissolved inorganic phosphorous).

\subsection{Laboratory procedures}

All macrofauna were identified to the lowest possible taxon and counted. Seagrass and macroalgal biomass was determined as ash free dry weight (AFDW) after oven drying at $60{ }^{\circ} \mathrm{C}$ for $72 \mathrm{~h}$ and combustion at $450{ }^{\circ} \mathrm{C}$ for $8 \mathrm{~h}$. The same procedure was used to quantify the organic matter content of the sediment.

\subsection{Macrobenthic trophic group assignments}

Each of the macrobenthic taxa was assigned to a trophic group based on feeding behaviour and food type. Trophic groups used in this study were surfacedeposit feeders (SDF), subsurface-deposit feeders (SsDF), suspension feeders (SF), carnivores (C), herbivores (H) and omnivores (O) (sensu Gaston, 1987; Gaston and Nasci, 1988; Gaston et al., 1995, 1997; Brown et al., 2000). Some species could not be confidently classified using the available schemes and these were entered as "unknown". Preliminary analysis included the snail Hydrobia ulvae, but it was also decided to analyse trophic structure omitting this species, since it occasionally occurred in very high numbers and its inclusion masked changes in other species.

\subsection{Data analysis}

\subsubsection{Macrofaunal diversity}

The diversity of the macrobenthic communities in the three areas was assessed and represented using rank-abundance curves (Molles, 1999) where the total number of ranks corresponds to species richness and evenness is reflected in the slope of the curve.

\subsubsection{Multivariate analysis of the macrofaunal assemblages}

The faunal samples were analysed using the nonmetric Multi-Dimensional Scaling (MDS) ordination method (Clarke and Warwick, 2001; Clarke and Gorley, 2001). 
Firstly, raw data were square-root-transformed in order to scale down the scores of the abundant species (Clarke and Warwick, 2001).

\section{Results}

\subsection{Seagrass and macroalgal biomass}

In the Z. noltii beds, total seagrass biomass decreased gradually throughout the study period (Fig. 2), but there was a clear seasonal pattern. During spring and summer, biomass increased substantially due to leaf growth and in autumn and winter, below ground biomass (rhizome and roots) represented about $50 \%$ of the total biomass. Green macroalgae biomass was low in this area while red macroalgae (Gracilaria sp.) were more abundant (Fig. 3A).

In the intermediate area, only small biomasses of green and red macroalgae were recorded all over the 3-year period (Fig. 3B).

In the most eutrophic area, there was a typical spring algal bloom (maximum of $452 \mathrm{~g}$ AFDW m ${ }^{-2}$, April 1993) during the first 6 months, followed by its sudden disappearance (crash) in late June (Fig. 3C). In contrast, in 1994, the biomass of green macroalgae was minimal, but in 1995, biomass was higher than the previous year $\left(111 \mathrm{~g} \mathrm{AFDW} \mathrm{m}^{-2}\right.$, April 1995).

\subsection{Diversity of the macrofauna}

The rank-abundance curves clearly show that the $Z$. noltii beds always had greater species richness than the most eutrophic area, with the intermediate zone having intermediate diversity (Fig. 4). Evenness increased from the Z. noltii beds to the most

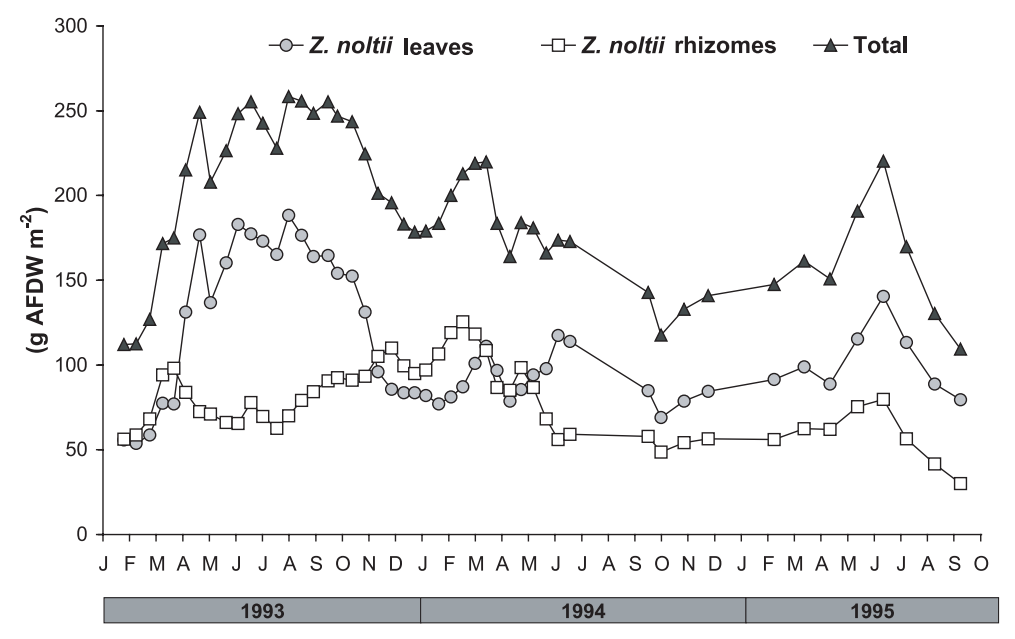

Fig. 2. Variation of Z. noltii biomass from January 1993 to September 1995. 

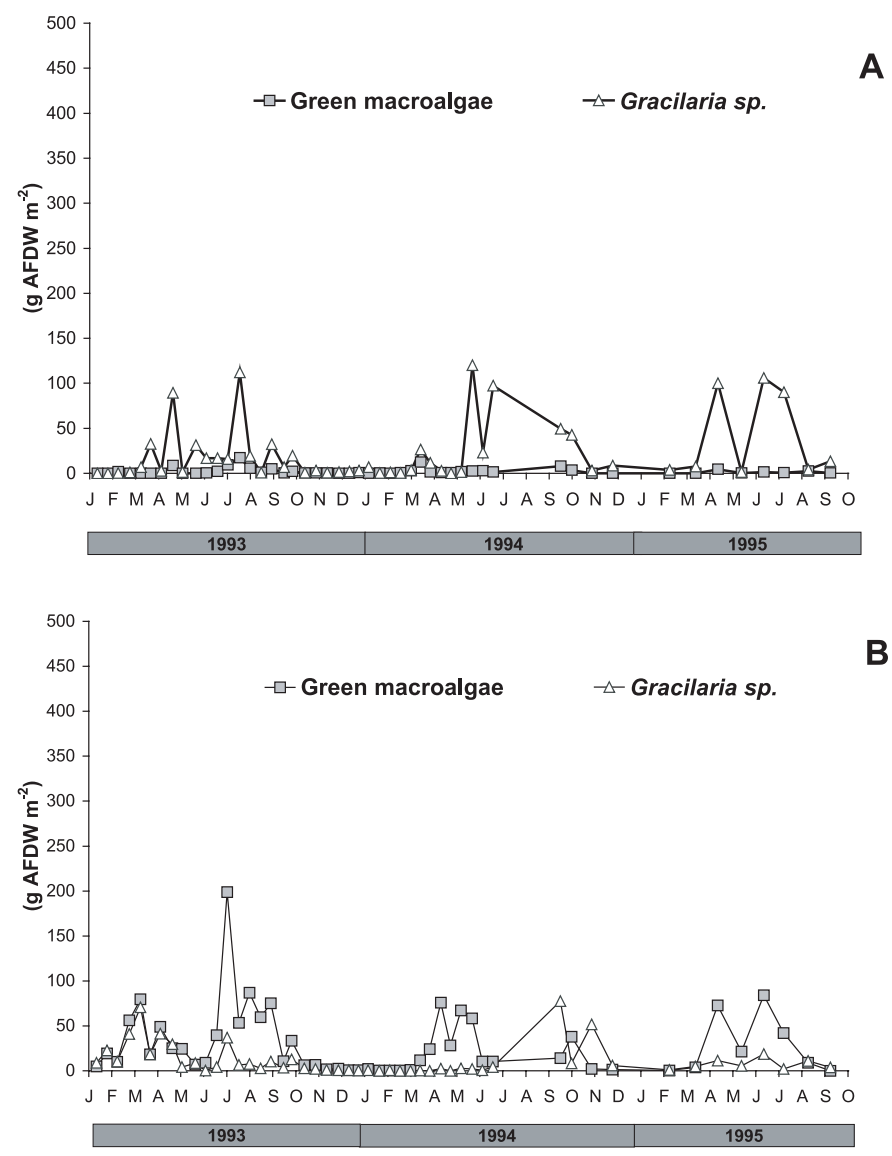

B

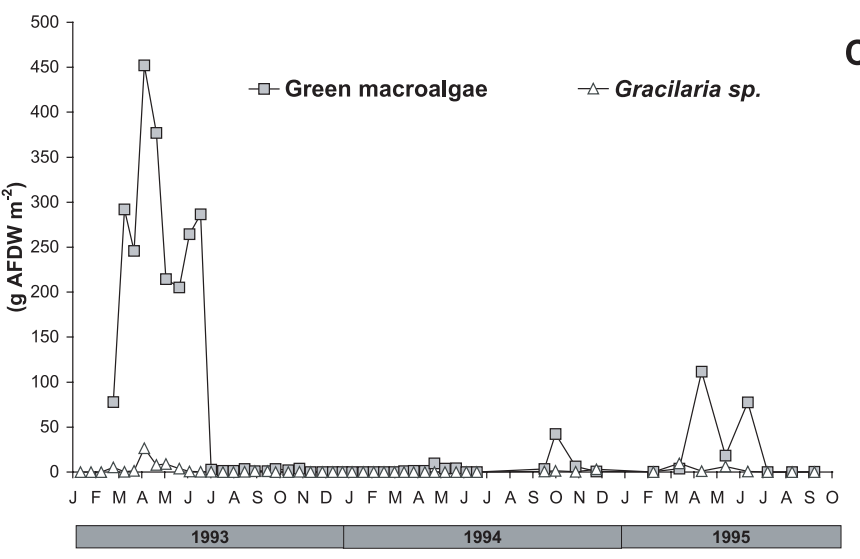

Fig. 3. Variation of algal biomass from January 1993 to September 1995. (A) Z. noltii beds; (B) intermediate area; (C) most eutrophic area. 
eutrophic area, due to the dominance of H. ulvae in the Z. noltii beds (see also Cardoso et al., 2002), reflected in the much steeper rank-abundance curve for the $Z$. noltii beds. If $H$. ulvae is omitted from the analysis, evenness appears higher in the Z. noltii beds.
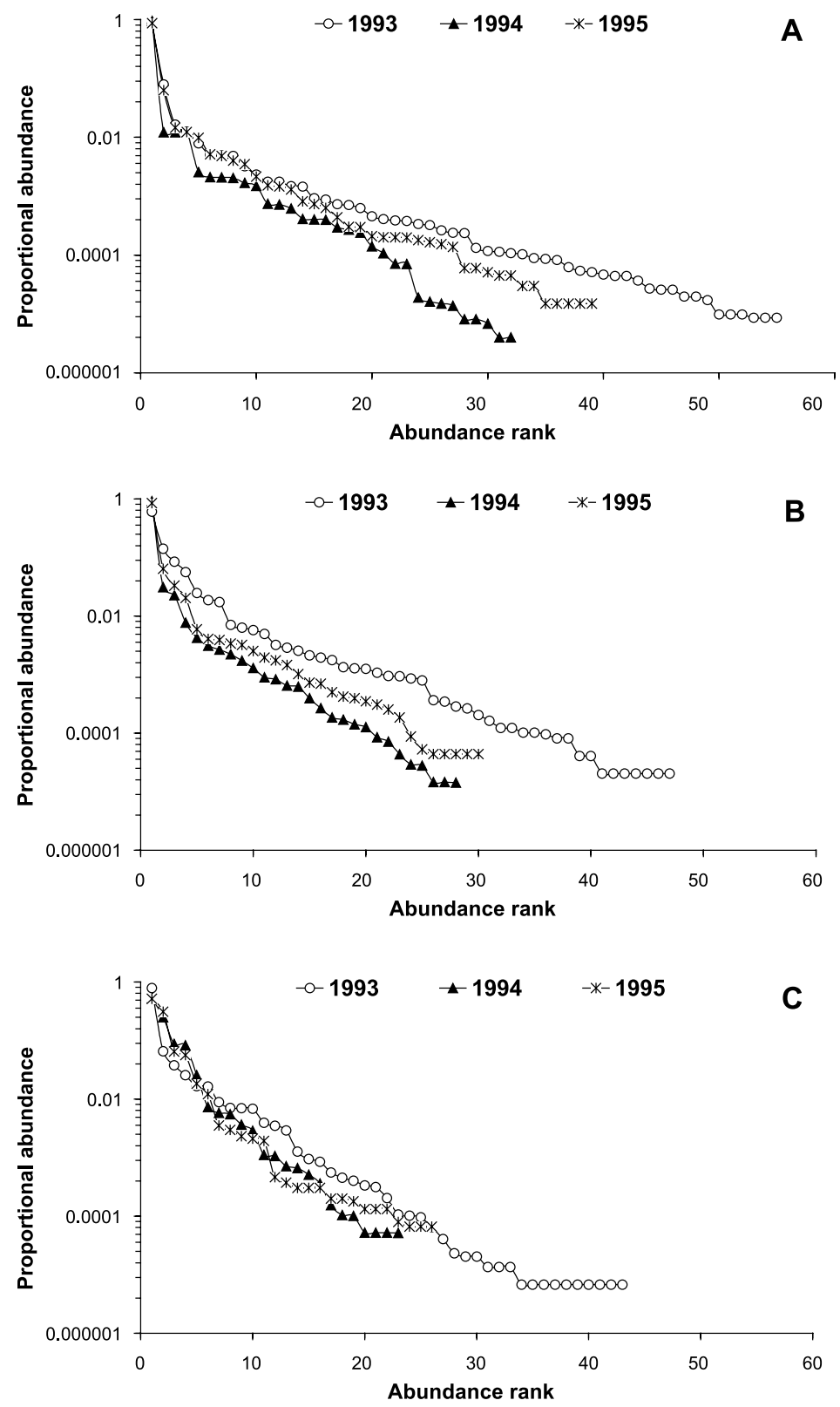

Fig. 4. Rank-abundance curves for three macrozoobenthic communities in the Mondego estuary. (A) Z. noltii beds; (B) intermediate area; (C) most eutrophic area. 
Species diversity declined throughout the 3 years of study in all three areas (Fig. 4). At the end of the study period, species richness in the Z. noltii beds (39 species) was similar to that observed in the most eutrophic area during the algal bloom (1993) (43 species), indicating a rapid deterioration of the seagrass habitat.

\subsection{Multivariate analysis of the macrofaunal assemblages}

The macrobenthic communities of the three study areas are spatially separated in the MDS plot, with the $Z$. noltii samples separated from those in the most eutrophic area by samples from the intermediate area (Fig. 5). Closer inspection shows that in the autumn of 1994 and the following winter (1995), the community of the Z. noltii beds was similar to that of the most eutrophic area (1993), consistent with the contention that the Z. noltii community is in decline. In addition, samples from the intermediate and most eutrophic areas showed the greatest scatter in the MDS plot, reflecting perhaps a greater instability of the environmental conditions of these areas.

Significant differences were detected by ANOSIM between the three sites. Z. noltii beds were significantly different from the intermediate area and from the most eutrophic area at the $5 \%$ level $(R=0.387 ; P=0.001 ; R=0.273 ; P=0.001$, respectively $)$. ANOSIM was also used to detect any differences between the 3 years. Significant differences were obtained between 1993 and $1994(R=0.192 ; P=0.02)$ and also between 1993 and 1995 $(R=0.206 ; P=0.016)$, but not between 1994 and $1995(R=-0.03, P=0.567)$.

\subsection{Trophic groups}

In the preliminary analysis, which included $H$. ulvae, we were unable to detect any significant modifications in community trophic structure, for either the spatial or

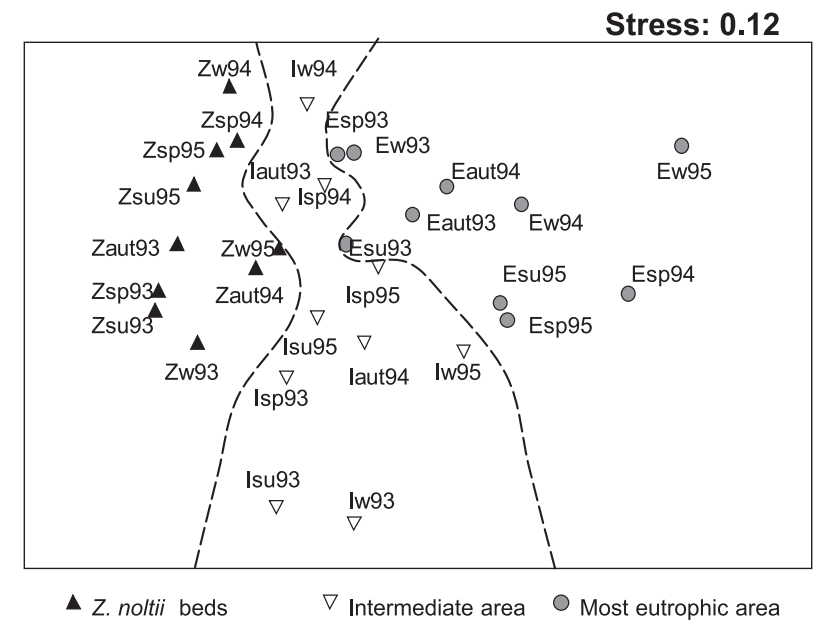

Fig. 5. Two-dimensional MDS ordination plot of macrobenthic communities. (Z) Z. noltii beds; (I) intermediate area; (E) most eutrophic area; (sp) spring; (su) summer; (aut) autumn; (w) winter. 


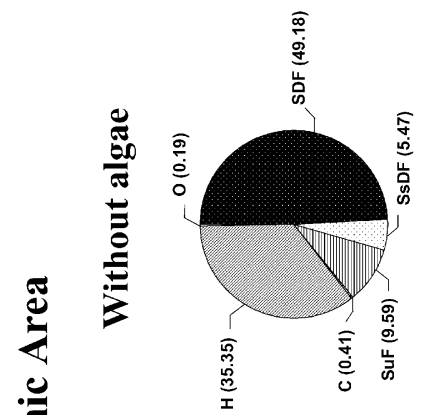

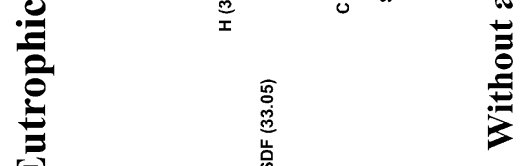
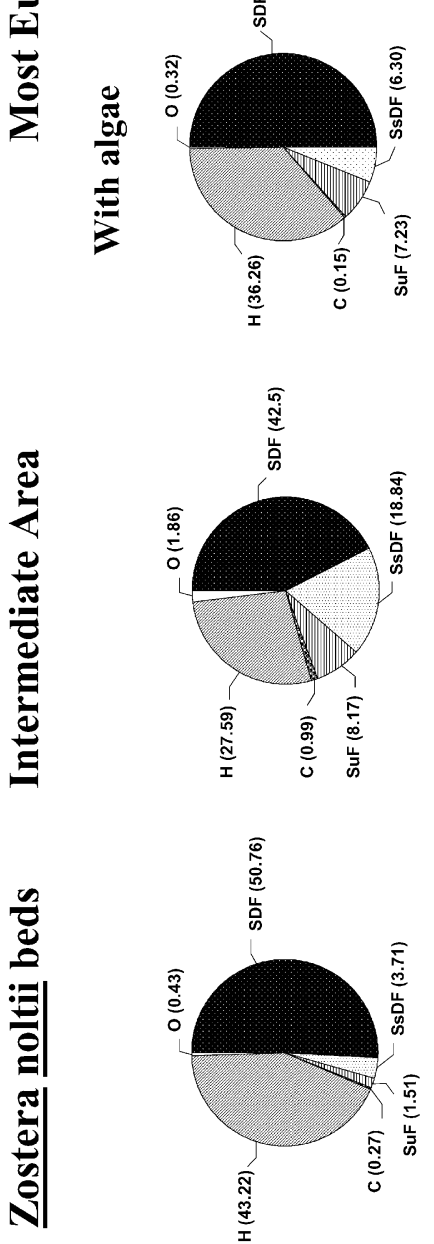

$\varangle$
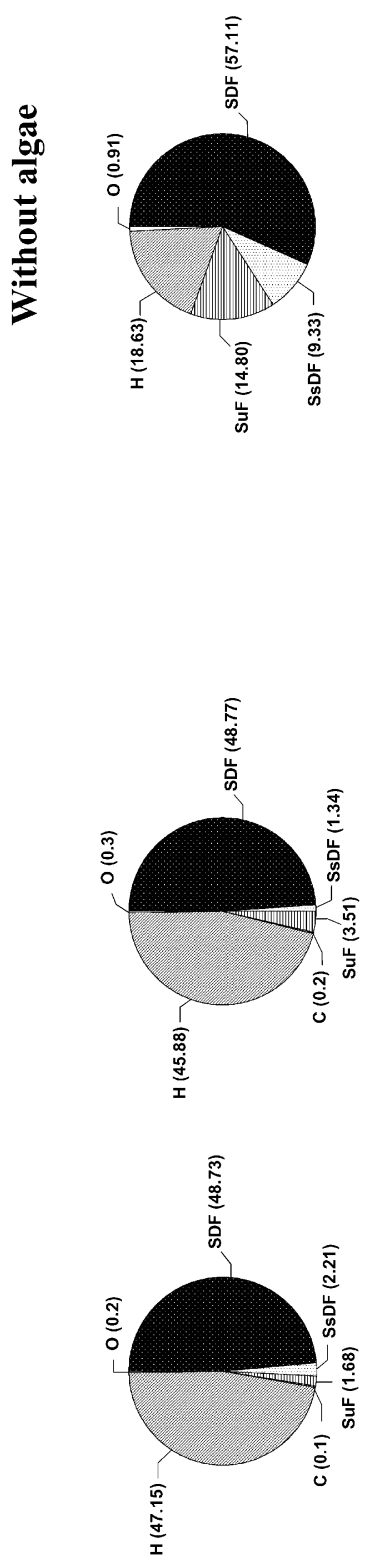

t66I
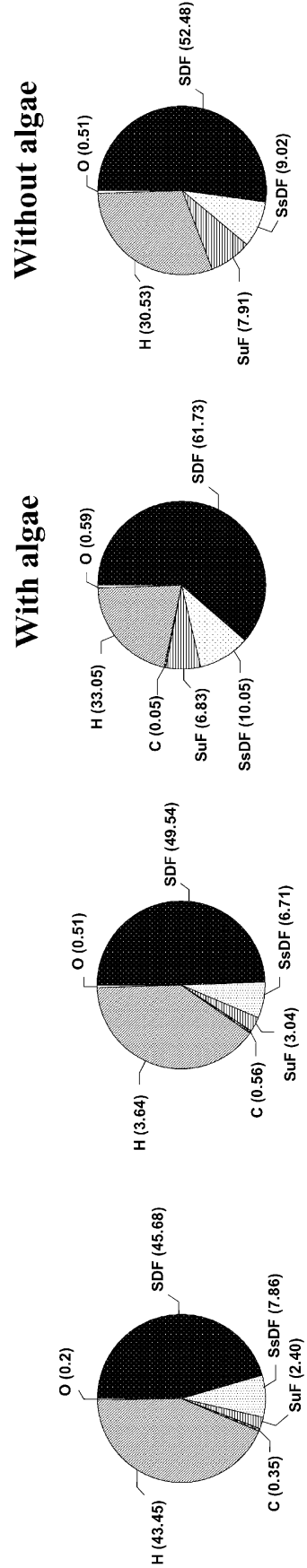

\$66I 


\section{Intermediate Area}
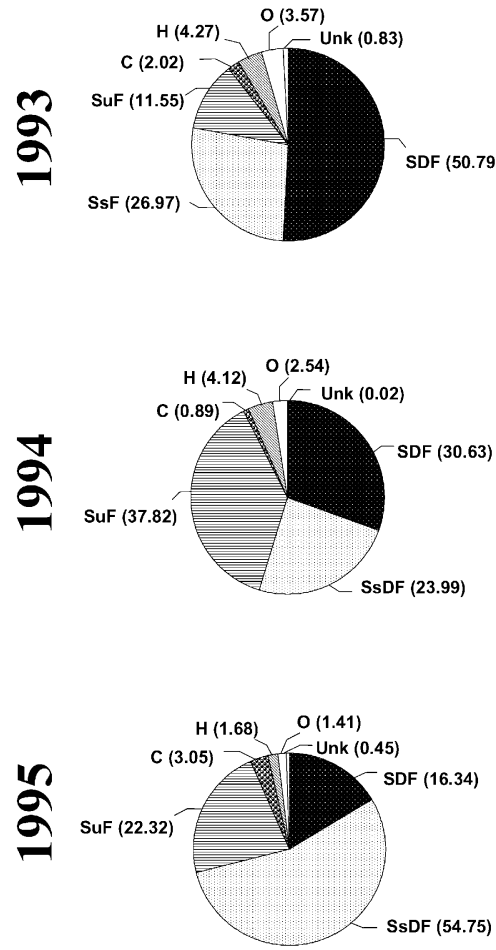
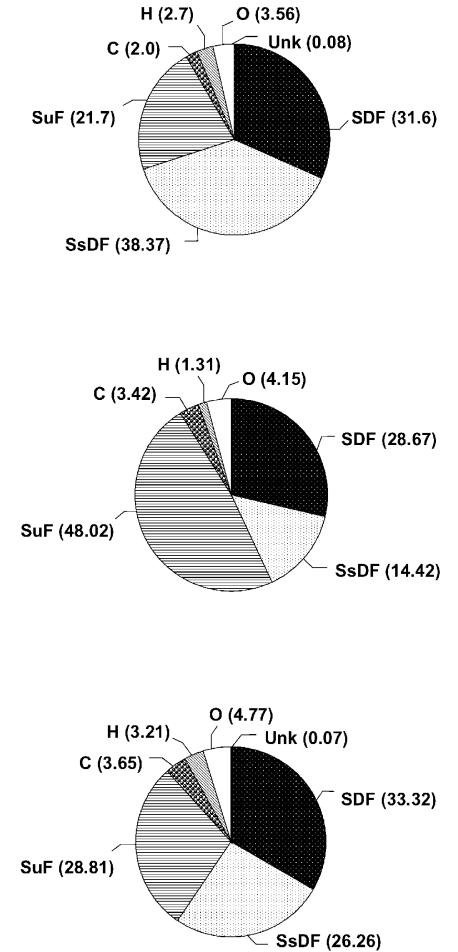

\section{Most Eutrophic Area}

With algae
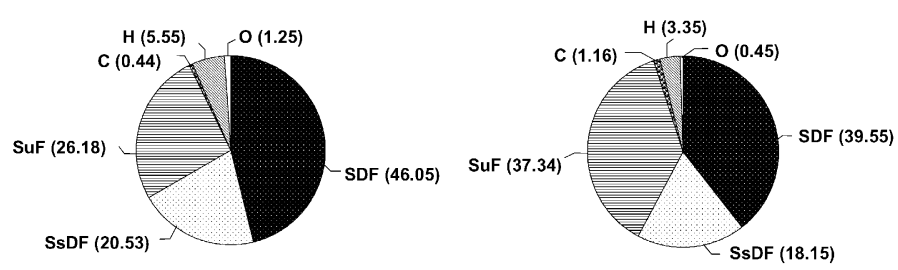

Without algae

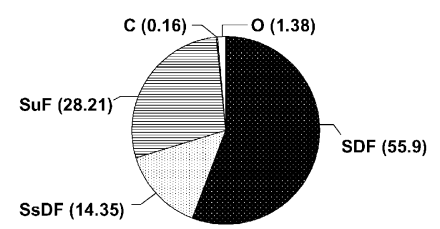

\section{With algae}

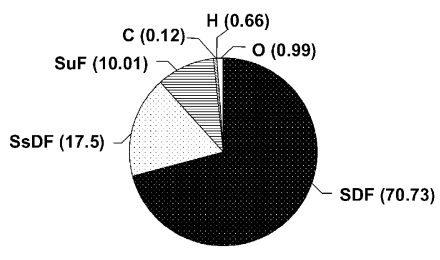

Without algae

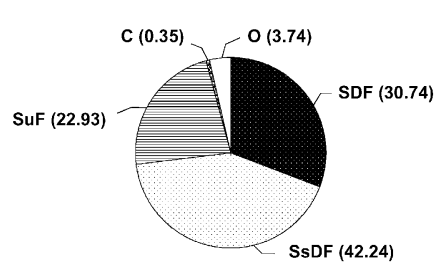

Fig. 6. Benthic assemblages of the Mondego estuary represented by trophic groups: surface-deposit feeders (SDF), subsurface-deposit feeders (SsDF), suspension feeders $(\mathrm{SuF})$, carnivores $(\mathrm{C})$, herbivores $(\mathrm{H})$ and omnivores $(\mathrm{O})$. Values are percentages of total individuals. (A) In the presence of H. ulvae; (B) in the absence of $H$. ulvae. 
temporal gradient. The most representative groups are the surface-deposit feeders and herbivores due to the dominance of $H$. ulvae, with other groups comprising a small fraction of the community (Fig. 6A).

Omitting $H$. ulvae revealed that the percentage of different trophic groups at the three sites changed considerably along the eutrophication gradient and also over the study period (Fig. 6B). Macrofaunal communities were dominated numerically by detritivores (surface-deposit feeders, subsurface-deposit feeders and suspension feeders), which together accounted for more than $90 \%$ of total macrobenthic abundance (Fig. 6). There was evidence of a gradual decline in the percentage of herbivores and subsurface-deposit feeders from the $Z$. noltii beds to the most eutrophic area, while the surface-deposit feeders and suspension feeders were more abundant in the upstream areas. Suspension feeders were more abundant in the intermediate area.

The trophic structure of the $Z$. noltii beds also changed over the 3-year period. Herbivores and surface-deposit feeders declined, followed by an increase in subsurface-deposit feeders. Carnivores increased over the 3 years whereas omnivores declined (Fig. 6B).

In the most eutrophic area, trophic structure showed greater variability over time probably due to the temporary occurrence of algal cover. Given that the presence of macroalgae can have a dramatic effect on macrofaunal trophic structure (Pearson and Rosenberg, 1978; Norkko and Bonsdorff, 1996a,b), a separate analysis was carried out for the years 1993 and 1995 (both of which experienced blooms) for periods with and without algal cover. This analysis indicated that the trophic structure of the most eutrophic area is more impoverished compared to that of the Z. noltii beds. Surface-deposit feeders represented the dominant group in all years, except in 1995 during the period without algae. Suspension feeders, which fluctuated widely with macroalgal events, were more abundant during the periods without macroalgae, when the available suspended organic matter was presumably higher.

The trophic structure of the intermediate area was much more erratic over time. Surface-deposit feeders were the only consistent group throughout the study. Carnivores and omnivores were more consistent over time in this area.

\section{Discussion}

Over the last 20 years, eutrophication of the south arm of the Mondego estuary has promoted major biological changes. Seagrass beds declined rapidly throughout the 19801990 period, macroalgal blooms increased and there have been marked changes in the macroinvertebrate assemblages, principally a progressive impoverishment of the most impacted, inner area (Marques et al., 1997; Lillebø et al., 1999; Lopes et al., 2000; Martins et al., 2001; Pardal et al., 2000; Cardoso et al., 2002). These estuary-scale, temporal trends are mirrored in the present, relatively small-scale $(1-2 \mathrm{~km})$ eutrophication gradient documented here over a 3-year period.

With respect to trophic groups, the invertebrate assemblages were dominated $(90 \%)$ by deposit-feeding species, indicative of the major role of detritus throughout the three sites. However, seagrass beds had more carnivores, herbivores and omnivores $(8 \%)$ than the most eutrophic area (4\%), and the percentage of herbivores and subsurface-deposit 
feeders decreased from seagrass beds to the most eutrophic area. In contrast, surfacedeposit feeders and suspension feeders increased from seagrass beds to the inner eutrophic area.

Interpreting these patterns is not straightforward. Seagrass beds provide a heterogeneous and complex habitat and thus support a higher diversity of both species and trophic groups, as reflected in our data. However, macroalgal blooms also create structural heterogeneity (Norkko and Bonsdorff, 1996a,b; Raffaelli et al., 1998) and may function as an enriched trophic resource, which can result in invertebrate assemblages of eutrophic areas being similar in structure to those of seagrass beds, as seems to have occurred in 1995. However, the benefits algae bring to the benthic fauna (habitat enhancement, food, refuge) are only temporary, because algal mats can shift position on the flats and they are highly seasonal. Also, macroalgal blooms have well-documented effects on the sediment physico-chemical environment and hence on invertebrate assemblages, but these may not be dose-dependent or monotonic (Raffaelli et al., 1998). A further complication is that over the 3 -year period, there was a general decline in species diversity, especially in the seagrass beds.

Notwithstanding the above, there was a consistently higher proportion of subsurfacedeposit feeders in finer sediment habitats of the seagrass bed, while surface-deposit feeders were more abundant in the more erosive sandy sediments of the eutrophic area. This coarse sediment area occasionally accumulated superficial detritus, but periodic scouring by currents removed this fine material (Gaston, 1987). Suspension feeders tended to be more abundant at the intermediate and most eutrophic areas, where, in the absence of vegetation cover, sediment resuspension and bedload transport are significant. Our results are broadly consistent with those of Bachelet et al. (2000) for French lagoons, although the trophic structure of the Mondego assemblages was much more dynamic through time. This probably reflects the progressive disappearance of seagrass at our site, which was relatively constant in the French study.

Our data are consistent with other, general eutrophication scenarios, viz. a replacement of one type of primary producer (seagrass) by another (macroalgae), declines in species diversity, and increase in detritivores and decline in herbivores and large increases in small deposit-feeding polychaetes (mainly Alkmaria romijni, Capitella capitata). Continued eutrophication is likely to lead to complete replacement of seagrass habitat in the Mondego by coarser sediments, mostly unvegetated except for occasional macroalgal blooms, and a variable invertebrate assemblage characterised mainly by opportunistic species. A central question that arises from this study is whether these changes are easily reversed. There is no shortage of policy instruments from the EC or nationally for addressing eutrophication in coastal areas and, although these are challenging to enact for socio-economic reasons, it would be technically possible to reduce nutrient enrichment in the Mondego. However, would the seagrass beds and their associated assemblages return? From the compelling evidence to date for seagrass beds in Australia (Kendrick et al., 2002) and northern Europe (e.g. Den Hartog, 1996; Van Katwijk and Hermus, 2000; Reise, 2002), we are not optimistic. The loss of seagrass from the eutrophic area of the Mondego and much of the intermediate area is associated with marked changes in the sediments of those areas, which have become coarser and more mobile, making re-colonisation by $Z$. noltii very difficult. The dynamics of this 
system may well contain the hysteresis described by Scheffer et al. (2001) for a range of ecological systems and by van de Koppel et al. (2001) for intertidal flats. Reestablishment of seagrasses under such conditions may require additional active restoration initiatives such as coastal engineering to modify the sediment regime and transplantation of seagrasses (Van Katwijk and Hermus, 2000; De Jonge et al., 2000), rather than relying on natural re-colonisation. In other words, by replacing lost ecosystem components as well as removing the key stressors (Hobbs and Nortton, 1996).

\section{Acknowledgements}

This paper was supported by the FCT (Portuguese Foundation for Science and Technology) through a grant attributed to P.G. Cardoso (SFRH/BD/5350/2001). The authors are indebted to all colleagues from IMAR-Coimbra who assisted in the field and laboratory work, and to Maria van Katwijk, University of Nijmegen, for sharing her ideas and experiences. [RW]

\section{References}

Bachelet, G., Montaudouin, X., Auby, I., Labourg, P.-J., 2000. Seasonal changes in macrophyte and macrozoobenthos assemblages in three coastal lagoons under varying degrees of eutrophication. J. Mar. Sci. 57, $1495-1506$.

Brown, S.S., Gaston, G.R., Rakocinski, C.F., Heard, R.W., 2000. Effects of sediment contaminants and environmental gradients on macrobenthic community trophic structure in Gulf of Mexico estuaries. Estuaries 23 (3), $411-424$.

Cardoso, P.G., Lillebø, A.I., Pardal, M.A., Ferreira, S.M., Marques, J.C., 2002. The effect of different primary producers on Hydrobia ulvae population dynamics: a case study in a temperate intertidal estuary. J. Exp. Mar. Biol. Ecol. 277 (2), 173-195.

Clarke, K.R., Gorley, R.N., 2001. Primer v5: User Manual/Tutorial. Primer-E, Plymouth.

Clarke, K.R., Warwick, R.M., 2001. Change in Marine Communities. An Approach to Statistical Analysis and Interpretation, 2nd ed. Primer-E, Plymouth.

De Jonge, V.N., de Jong, D.J., Katwijk, M.M., 2000. Policy plans and management measures to restore eelgrass (Zostera marina L.) in the Dutch Wadden Sea. Helgol. Mar. Res. 54, 151-158.

Den Hartog, C., 1996. Sudden declines of seagrass beds: "wasting disease" and other disasters. In: Kuo, J., Phillips, R.C., Walker, D.I., Kirkman, H. (Eds.), Seagrass Biology. Proceedings of an International Workshop, Rottnest island, Western Australia. University of Western Australia, Nedlands, pp. 307-314.

Den Hartog, C., Phillips, R.C., 2000. Seagrasses and benthic fauna of sediment shores. In: Reise, K. (Ed.), Ecological Comparisons of Sedimentary Shores. Springer, Berlin, pp. 195-212.

Dolbeth, M., Pardal, M.A., Lillebø, A.I., Azeiteiro, U.M., Marques, J.C., in press. Short and long-term effects of eutrophication on the secondary production of an intertidal macrobenthic community. Mar. Biol.

Duarte, C.M., 1995. Submerged aquatic vegetation in relation to different nutrient regimes. Ophelia 41, 87-112.

Duarte, C.M., 2000. Marine biodiversity and ecosystem services. J. Exp. Mar. Biol. Ecol. 250, 117-132.

Flindt, M.R., Kamp-Nielsen, L., Marques, J.C., Pardal, M.A., Bocci, M., Bendoricchio, G., Salomonsen, J., Nielsen, S.N., Jørgensen, S.E., 1997. Description of the three shallow estuaries: Mondego River (Portugal), Roskilde Fjord (Denmark) and the lagoon of Venice (Italy). Ecol. Model. 102, 17-31.

Gaston, G.R., 1987. Benthic polychaeta of the middle Atlantic Bight: feeding and distribution. Mar. Ecol. Prog. Ser. $36,251-262$. 
Gaston, G.R., Nasci, J.C., 1988. Trophic structure of macrobenthic communities in the Calcasieu estuary, Louisiana. Estuaries 11 (3), 201-211.

Gaston, G.R., Brown, S.S., Rakocinski, C.F., Heard, R.W., Summers, J.K., 1995. Trophic structure of macrobenthic communities in northern Gulf of Mexico estuaries. Gulf Res. Rep. 9 (2), 111-116.

Gaston, G.R., Cleveland, C.M., Brown, S.S., Rakocinski, C.F., 1997. Benthic-pelagic coupling in northern Gulf of Mexico estuaries: do benthos feed directly on phytoplankton? Gulf Res. Rep. 9 (4), $231-237$.

Hobbs, R.J, Nortton, D.A, 1996. Towards a conceptual framework for restoration ecology. Restor. Ecol. 4, 93- 110 .

Kendrick, G.A., Aylward, M.J., Hegge, M.L., Cambridge, K., Hillman, K., Wyllie, A., Lord, D.A, 2002. Changes in seagrass coverage in Cockburn Sound, Western Australia between 1967 and 1999. Aquat. Bot. 73, $75-87$.

Lillebø, A.I., Pardal, M.A., Marques, J.C., 1999. Population structure, dynamics and production of Hydrobia ulvae (Pennant) (Mollusca: Prosobranchia) along an eutrophication gradient in the Mondego estuary (Portugal). Acta Oecol. 20 (4), 289-304.

Lopes, R.J., Pardal, M.A., Marques, J.C., 2000. Impact of macroalgal blooms and wader predation on intertidal macroinvertebrates: experimental evidence from the Mondego estuary (Portugal). J. Exp. Mar. Biol. Ecol. $249,165-179$.

Marques, J.C., Rodrigues, L.B., Nogueira, A.J.A., 1993a. Intertidal macrobenthic community structure in the Mondego estuary (Western Portugal): reference situation. Vie Milieu 43 (2-3), 177-187.

Marques, J.C., Maranhão, P., Pardal, M.A., 1993b. Human impact assessment on the subtidal macrobenthic community structure in the Mondego estuary (Western Portugal). Estuar. Coast. Shelf Sci. 37, 403-419.

Marques, J.C., Pardal, M.A., Nielsen, S.N., Jørgensen, S.E., 1997. Analysis of the properties of exergy and biodiversity along an estuarine gradient of eutrophication. Ecol. Model. 102, 155-167.

Martins, I., Pardal, M.A., Lillebø, A.I., Flindt, M.R., Marques, J.C., 2001. Hydrodynamics as a major factor controlling the occurrence of green macroalgal blooms in a eutrophic estuary: a case study on the influence of precipitation and river management. Estuar. Coast. Shelf Sci. 52, 165-177.

Molles, M.C., 1999. Ecology. Concepts and Applications. WCB/McGraw-Hill, Dubuque, IA. 509 pp.

Niell, F.X., et al., 1996. Spanish Atlantic coasts. In: Schramm, W., Nienhuis, P.H. (Eds.), Marine Benthic Vegetation. Recent Changes and the Effects of Eutrohication. Springer, Berlin, pp. 265-282.

Nienhuis, P.H., 1996. The North Sea coasts of Denmark, Germany and the Netherlands. In: Schramm, W., Nienhuis, P.H. (Eds.), Marine Benthic Vegetation. Recent Changes and the Effects of Eutrohication. Springer, Berlin, pp. 187-222.

Norkko, A., Bonsdorff, E., 1996a. Population responses of coastal zoobenthos to stress induced by drifting algal mats. Mar. Ecol. Prog. Ser. 140, 141-151.

Norkko, A., Bonsdorff, E., 1996b. Rapid zoobenthic community responses to accumulations of drifting algae. Mar. Ecol. Prog. Ser. 131, 143-157.

Oliveira, J.C., Cabecadas, G., 1996. Portugal. In: Schramm, W., Nienhuis, P.H. (Eds.), Marine Benthic Vegetation. Recent Changes and the Effects of Eutrohication. Springer, Berlin, pp. 283-293.

Pardal, M.A., Marques, J.C., Metelo, I., Lillebø, A.I., Flindt, M.R., 2000. Impact of eutrophication on the life cycle, population dynamics and production of Ampithoe valida (Amphipoda) along an estuarine spatial gradient (Mondego estuary, Portugal). Mar. Ecol. Prog. Ser. 196, 207-219.

Pearson, T.H., Rosenberg, R., 1978. Macrobenthic succession in relation to organic enrichment and pollution of the marine environment. Oceanogr. Mar. Biol. Ecol. 20, 1-41.

Raffaelli, D.G., Raven, J.A., Poole, L.J., 1998. Ecological impact of green macroalgal blooms. Oceanogr. Mar. Biol. 36, 97-125.

Reise, K., 2002. Sediment mediated species interactions in coastal waters. J. Sea Res. 48, 127-141.

Reise, K., Heere, E., Sturm, K., 1989. Historical changes in the benthos of the Wadden Sea around the island of Sylt in the North Sea. Helgol. Meeresunters. 43, 417-433.

Scheffer, M., Carpenter, S., Foley, J.A., Folke, C., Walker, B., 2001. Catastrophic shifts in ecosystems. Nature $413,591-596$.

Schramm, W., 1996. Conclusions. In: Schramm, W., Nienhuis, P.H. (Eds.), Marine Benthic Vegetation. Recent Changes and the Effects of Eutrohication. Springer, Berlin, pp. 449-456.

Schramm, W., Nienhuis, P.H. (Eds.), 1996. Marine Benthic Vegetation. Recent Changes and the Effects of Eutrohication. Springer, Berlin. 465 pp. 
Van de Koppel, J., Herman, P.M.J., Thoolen, P., Heip, C.H.R., 2001. Do alternate stable states occur in natural systems? Evidence from a tidal falt. Ecology 82, 3449-3461.

Van Katwijk, M.M., Hermus, D.R., 2000. Effects of water dynamics on Zostera marina: transplantation experiments in the intertidal Dutch Wadden Sea. Mar. Ecol. Prog. Ser. 208, 107-118.

Widdows, J., Brinsley, M.D., 2002. Impact of biotic and abiotic processes on sediment dynamics and the consequences to the structure and functioning of the intertidal zone. J. Sea Res. 48 (2), 143-156. 